\title{
Industry warms to 'flexible' carbon cuts
}

London. A study appearing to suggest that, rather than making major and immediate cuts in carbon emissions to combat global warming, governments should make moderate reductions now, followed by sharper reductions later, has become the latest focus of controversy in the debate about man-made climate change.

At a conference on the economics of climate change organized by the oil industry in Paris two weeks ago, the study, published in Nature earlier this year (379, $240 ;$ 1996), was widely heralded by representatives of the industry as a typical example of a 'flexible' approach to emissions reductions.

This response coincides with an apparent shift in the industry's strategy. Having now acknowledged the need to combat global warming, it is warning that proposed controls on carbon dioxide emissions will be vigorously opposed if they are considered too costly to implement.

But environmental organizations, and a few industrialists, criticize the paper for appearing to advocate a 'delay or do nothing' policy. Some scientists and economists point out that it represents only one opinion in a controversial field, and should not be used as the sole basis for making policy. Others criticize any efforts to quantify such as the effects on biodiversity and the environment.

The conference was organized by the International Petroleum Industry Environmental and Conservation Association, based in London. Its goal appears to have been to counter the effectiveness of the environmentalist movement in dominating the climate change agenda. Organizations such as Greenpeace and the World Wide Fund for Nature have forced the pace of debate since the Earth Summit in Rio de Janeiro five years ago, when they helped to persuade governments voluntarily to reduce carbon dioxide emissions to 1990 levels by 2000 .

A new proposed law to curb emissions must be agreed at the next annual conference of the United Nations climate the 'non-market' impact of climate change,

convention in Kyoto, Japan, in December 1997. This time, the oil industry is keen not to be left behind.

Environmentalists, working in association with the Alliance of Small Island States, are calling for a further 20 per cent reduction in carbon dioxide emissions by 2005 . But this is strongly opposed by many developed and developing countries, who fear it could impede their industrialization. It is also

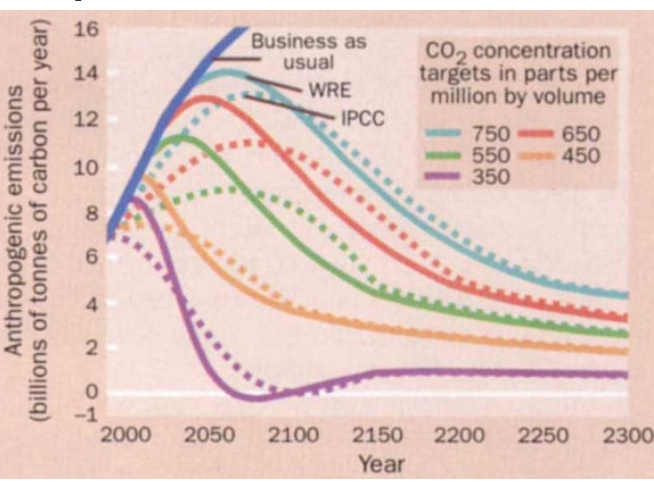

A comparison of IPCC proposals with those of Wigley, Richels and Edmonds (WRE) for stabilizing atmospheric carbon dioxide at five levels. WRE say the least costly option is moderate emissions cuts in the early years followed by sharper reductions later.

opposed by oil-exporting countries, which forecast a drastic reduction in export income, and by the oil industry, whose profits would be reduced.

The oil industry's desire for a flexible approach to emissions reductions - which would have minimal impact on economic growth - appears to be shared by the US administration.

At the Paris conference, the industry marshalled scientific backing for its stance. For example, it drew on evidence presented by Richard Richels of the US Electric Power Research Institute, a co-author of the Nature paper that says countries would save money by delaying sharp reductions in emissions.

The paper, whose authors include Tom Wigley, a senior scientist at the US National Centre for Atmospheric Research and an adviser to the UN's Intergovernmental Panel on Climate Change, says that there is

\section{California drops plan to destroy records}

San Francisco. California's Environmental Protection Agency has scrapped a controversial plan to destroy records of dissenting scientific opinions on environmental hazards (see Nature 470,$383 ; 1996$ ).

The agency had ordered scientists to eliminate research data and other records on the health risks of industrial emissions and other pollutants if the documents did not agree with its policy directives. But a public-interest lawsuit prompted officials to suspend and reconsider the policy while the state attorney general's office reviewed the legal ramifications.

The Natural Resources Defense Council (NRDC), the Environmental Law Center and the Society of Professional Journalists had jointly filed a suit against the agency, arguing that the policy represented bad scientific practice and violated California's laws on open records. "The policy was blatantly illegal," says Al Meyerhoff, senior attorney with the NRDC. The groups are not prepared to drop their lawsuit until they are confident that the policy has never been implemented, he says. more than one route to stabilizing atmospheric concentrations of carbon dioxide (see figure). The researchers suggest that modest emission reductions early on will give governments time to free up the required extra capital, and to develop lowercost technologies, and thus to reduce the costs of sharper cuts in carbon dioxide emissions in the future.

Richels reiterated the paper's conclusions at the Paris meeting, but this time using cost-benefit analysis. $\mathrm{He}$ produced monetary estimates of the impact on national economies, environment, biodiversity and human health if average global temperatures rose by $2.5^{\circ} \mathrm{C}$ following a doubling of atmospheric carbon dioxide concentrations.

He said there were "strong arguments" for concluding that the high costs of an immediate heavy emissions reduction programme might outweigh the potential savings, unless the bulk of 'non-market' damages from climate change occur earlier than expected.

But Michael Grubb, of the Royal Institute of International Affairs in London, says Wigley and Richels have not fully assessed the costs of shifting the burden of emission reductions to a later date. Grubb also questions whether cheaper, less carbon-intensive fuels would emerge without governments providing incentives, which has not yet happened.

Another critic is David Madison of the Centre for Social and Economic Research on the Global Environment in London. Madison says he is concerned that Richels has tried to put values on the damage to biodiversity and the environment from climate change, when there is little expert consensus either on the magnitude or the valuation of potential losses.

Wigley says those who think his Nature paper advocates a delay in cutting carbon dioxide emissions "are just plain wrong". Many of his critics have "totally misunderstood the paper". For their benefit, he has written a three-page 'plain language guide'.

Wigley says he is aware that some see a connection between the facts that the paper's conclusions support US policy, and that two of its authors, Richels and Jae Edmonds, work for the US electricity supply industry and the Department of Energy respectively. But he says any suggestions of bias are "extremely inappropriate".

"Both my co-authors are reputable scientists of the highest international standing, who have published extensively in the peer-reviewed literature," he says. "It is not true to say that scientists don't have their individual political biases. Assumptions can be subjective, especially in economics. But these assumptions usually come out in the wash during peer review." Ehsan Masood 